\title{
MAGNET POWER SUPPLY RELIABILITY AT THE ADVANCED PHOTON SOURCE*
}

\author{
A. Hillman ${ }^{\dagger}$, J. Carwardine, G. Sprau \\ Advanced Photon Source, Argonne National Laboratory, Argonne, IL
}

\begin{abstract}
Operational goals for the Advanced Photon Source facility include $95 \%$ user availability and a mean time between unscheduled beam losses of 30 hours, with 5,000 user hours of scheduled beam per year. To meet these goals, operational goals for the magnet power supply system have been set at $99 \%$ availability, with a mean time between faults of 200 hours. The large number of power converters (1,400 in the storage ring alone), complexity of the overall systems, and limited machine shutdown time make meeting these goals particularly challenging. During fiscal year 2000, power supply system availability was close to $99 \%$, but the mean time between faults was only 85 hours. Efforts are ongoing to incrementally improve power supply reliability and to meet the operational goals. This paper presents important power supply operational statistics and describes our approach to meeting the reliability goals.
\end{abstract}

\section{OVERVIEW}

The Advanced Photon Source (APS) storage ring contains some 1,400 power supplies. Each multipole and corrector magnet is separately powered, with only the main dipole magnets on a common bus [1]. The separate power supplies provide increased flexibility for the storage ring, but place additional demands on power supply reliability. The APS reliability goals are $95 \%$ availability and 50 hours mean time to unscheduled beam loss, with 5,000 user hours scheduled per year. The present annual operating schedule provides for four user runs (typically 7 to 10 weeks long), and four machine shutdowns (typically 3 to 5 weeks long). There is one 48 -hour period and one 8hour period of machine studies/intervention for every two weeks of user operation.

Reliability goals for the magnet power supply systems are $99 \%$ availability, with a mean time between beam losses of 200 hours. Because a failure of any one magnet power supply can cause loss of stored beam, this goal translates to a required mean time between power-supplyrelated beam trips (MTBF) of better than 250,000 hours for each magnet power supply. In the past, the power supply systems have not consistently met these goals, and efforts are ongoing to improve reliability.

\footnotetext{
*Work supported by U.S. Department of Energy, Office of Basic Energy Sciences, under Contract No. W-31-109-ENG-38.

†Hillmana@aps.anl.gov
}

If we average the power supply downtime since the start of calendar year 2000, we are very close to our target goal. The implementation of such improvements is particularly challenging because of the number of power supplies involved, and because of the potential to create new problems by simply disturbing the equipment.

Statistical data on power supply reliability comes from two sources. First, detailed records are maintained by APS Operations Groups to keep track of reasons for lost fills and machine downtime. Second, the APS Power Supply Group maintains detailed information on equipment failures and repairs.

Although machine availability and mean time to beam loss (fault rates) are both key performance indicators, most of the discussion in this paper concerns faults that have a direct effect on machine availability.

Table 1 shows yearly power supply (PS) reliability statistics for fiscal year 1998 to 2001 with power supply downtime percentage of delivered beam time, MTBF, and mean time to repair/recovery (MTTR). For the past two years, downtime has been close to the goal of $1 \%$, but MTBF has been significantly below our goal of 200 hours. More detailed run-by-run statistics are shown in Figures 1 and 2, together with trendlines that use a moving average of four runs. Again these data show that overall power supply downtime has been close to the goal of $1 \%$, but the MTBF is below our stated goal.

Table 1: Power Supply Overall Statistics

\begin{tabular}{|l|c|c|c|}
\hline & $\begin{array}{c}\text { PS } \\
\text { Downtime } \\
(\%)\end{array}$ & $\begin{array}{c}\text { MTBF } \\
\text { (Hours) }\end{array}$ & $\begin{array}{c}\text { MTTR } \\
\text { (Hours) }\end{array}$ \\
\hline FY98 & $1.93 \%$ & 118.95 & 2.47 \\
\hline FY99 & $1.37 \%$ & 89.96 & 1.30 \\
\hline FY00 & $0.96 \%$ & 86.36 & 0.88 \\
\hline FY01 & $1.04 \%$ & 142.84 & 1.55 \\
\hline
\end{tabular}




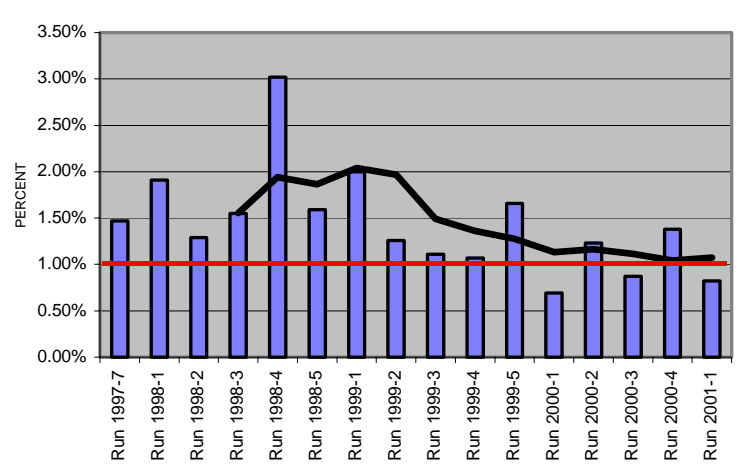

Figure 1: Percent of downtime based on total user hours.

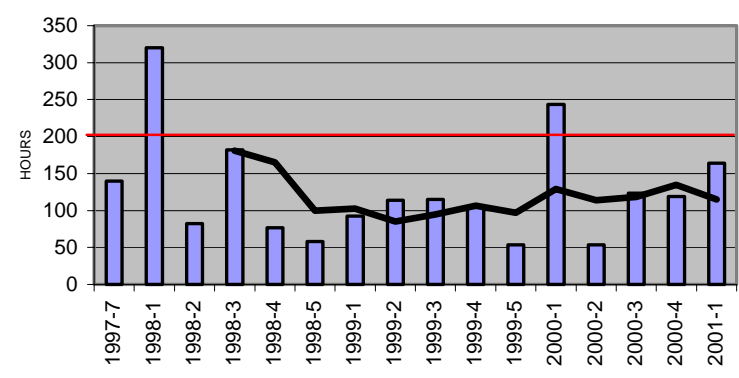

Figure 2: Power supply mean time between faults.

\section{DEFINING THE PROBLEMS}

As might be expected given the large number of power converters, several recurring reliability problems have been identified. Furthermore, greater than half of the power-supply-induced beam loss events during FY98-00 were caused by nuisance trips. Within the category of nuisance trip, we found two recurring problems with communication of power supply setpoints, where the setpoints would spuriously drop to zero or go to the wrong value when commanded to change. Table 2 shows a breakdown of such beam loss events. It is evident that resolving the nuisance trips alone would have a major impact on availability.

Table 2: Power Converter Induced Beam Loss Events

\begin{tabular}{|c|c|c|c|}
\hline & $\begin{array}{c}\text { Setpoint } \\
\text { Error }\end{array}$ & $\begin{array}{c}\text { Other } \\
\text { Nuisance } \\
\text { trips }\end{array}$ & $\begin{array}{c}\text { Converter } \\
\text { Failures }\end{array}$ \\
\hline FY 98 & 3 & 16 & 10 \\
\hline FY 99 & 16 & 7 & 18 \\
\hline FY 00 & 9 & $17+11$ & 7 \\
\hline FY 01 & 2 & 0 & 6 \\
\hline
\end{tabular}

Includes failures only during user studies.

It should be noted that the number of total nuisance trips during FY00 was 28, but 11 of those were caused by a control interface modification that had some unexpected side effects that were quickly resolved.

\subsection{Recurring Equipment Problems}

To improve reliability, we needed to analyze and define the problems. To do this, we looked at the past few years' of fault history to see if any one item had a major impact on the performance of the converters.

Table 3: Most Frequent Converter Failures Since FY98

\begin{tabular}{|c|c|c|c|c|c|}
\hline & $\begin{array}{c}\text { Switching } \\
\text { on/off } \\
\text { 180v }\end{array}$ & $\begin{array}{c}\text { CTL } \\
\text { Power } \\
\text { Board }\end{array}$ & $\begin{array}{c}\text { Shunt } \\
\text { Water } \\
\text { Leaks }\end{array}$ & $\begin{array}{c}\text { Noise } \\
\text { (EMI) }\end{array}$ & $\begin{array}{c}\text { Loss of } \\
\text { Setpoint }\end{array}$ \\
\hline FY98 & 58 & 49 & 17 & 32 & 35 \\
\hline FY99 & 31 & 11 & 0 & 38 & 11 \\
\hline FY00 & 31 & 5 & 6 & 0 & 6 \\
\hline FY01 & 2 & 2 & 0 & 0 & 3 \\
\hline
\end{tabular}

Includes failures during both startup and user studies.

The above chart shows five distinct areas that we identified as focal points. We also found a need for specialized diagnostic tools.

\subsection{Startup Problems}

It is well known that electronics equipment is more likely to fail at power-on than at any other time. This issue particularly impacts power supply restart after a machine shutdown. Figure 3 shows faults by weeks of machine runs throughout fiscal years 1999 and 2000 (usually 7 to 11 weeks in duration). The increased fault rate in week 7 was a consequence of two periods of extreme weather that caused power outages sitewide.

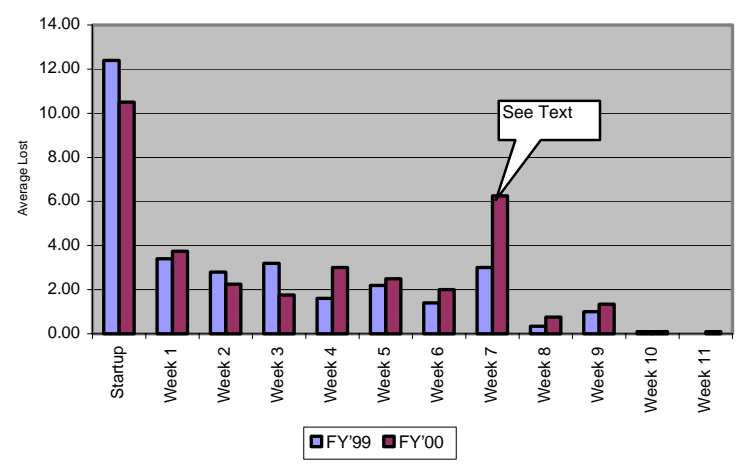

Figure 3: Average SR converters lost per week after a shutdown period.

Typically, the first 24 hours following a machine shutdown are spent in 'startup,' re-establishing, and retesting power supplies. Converters are run through a series of tests, including a full-power test and a digital to analog converter (DAC) resolution test. Perhaps surprisingly, the number of converters that fail during each startup has not changed significantly over the past two years, remaining around 10 converter failures per startup. This is in spite of ongoing efforts to reduce failure rates. 


\section{SPECIFIC PROBLEMS ADDRESSED}

\subsection{0-Volt DC Power System}

The converter electronics are powered from a distributed 180-V DC bus. At the system restart, there can be a rather large noise transient that does affect some components. This effect causes the "weakening" of components and is, for the most part, a gradual process and therefore somewhat random. One recent improvement was to modify electrical power feeds to the control electronics for the power converters. Prior to December 2000, main power and control power were fed from the same electrical source, which meant that the control electronics were powered off during accelerator tunnel accesses (including machine shutdowns). During the December 2000 shutdown, this process was changed to allow control electronics to remain energized, even during Lockout/Tagout of the main power feeds. The main 480$\mathrm{V}$ feed to the $180-\mathrm{V}$ DC bus system has been upgraded with surge suppressers.

\subsection{Control Power Supply Board}

The basic design of this supply was patterned after the fly-back circuit of a TV. The concept was good but, in the end, it needed improvements. Due to the lack of electrical magnet interference (EMI) shielding and with the ease the supply could be overloaded the supply has a slightly higher failure rate. The control power boards are being replaced with commercial supplies that can accept design improvements. The replacement supplies have reduced the overall noise considerably.

\subsection{Shunt Water Leaks}

We used a water-cooled shunt, and we enclosed it in PVC to provide water cooling, electrical isolation, keep cost down, and make replacing parts (if required) easer. The current demand had increased to the design upper level and was being maintained for longer periods of time. The water-cooled shunt has been changed to a Hall-effect device manufactured by LEM USA. This device is aircooled, with better temperature stability.

\subsection{Noise (EMI)}

As a group, we took care to design for noise protection with 15-V logic, ground planes, etc.; however, there was one area that was overlooked: the inside of the converters for EMI. The EMI was largely attributed to electrical noise from the control power board. There was a simple solution: changing the drive for the opto-islators and upgrading the control power boards.

\subsection{Loss of Setpoints}

The problems with the loss of setpoint have already been discussed. Several marginal design issues have been identified and resolved. There is evidence that the frequency of these events has been reduced, although there has not been sufficient operating experience to determine whether these issues have been completely resolved.

\subsection{Specialized Diagnostic Tools}

To date, we have made changes to all the stated impact items. To aid in the diagnosis of these problems, we found that we needed specialized diagnostic tools. This was highlighted when the hunt for problems, the normal tests for regulation, slew rate, bit checks repeatability, etc. did not show the whole picture. Intermittent problems showed up only once a day or once a week; thus, we needed a tool to find and record these occurrences, identify trends, and do it at a reasonable rate. We have developed a specialized diagnostic tool that can monitor signals at a $100-\mathrm{Hz}$ rate [2]. A second tool has been developed to help to identify converters that may have regulation problems. The tool uses the system BPMs to detect beam motion and narrow down the source to a suspect sector and even to a group of converters [3]. The goal for this tool is to quickly identify individual converters that may glitch or have a relatively noisy output so they can be replaced.

\section{CONCLUSION}

Continuing efforts to provide a more robust and reliable power supply system are ongoing at APS. Several problems have already been identified and resolved. While resolution is ongoing for others, we believe the right approach is being taken and overall reliability goals will be met.

\section{ACKNOWLEDGMENTS}

The continuing efforts by all members of the Power Supply Group are recognized as critical to meeting the reliability goals discussed in this paper. We particularly wish to acknowledge contributions by the following individuals: Bill Brzowski, David Donkers, Mark Gibson, Jeff Goetzen, Jim Klick, Bernard Kudirka, Philip McNamara, Tony Puttkammer, Roy Seglem, and Rob Vargas.

\section{REFERENCES}

[1] D.G. McGhee, "Circuit Description of Unipolar DC-to-DC Converters for APS Storage ring Quadrupoles and Sextupoles," Particle Accelerator Conference, 1993. pp. 1271-1273.

[2] T. Fors et al., "A Method of Measuring Noise and Detecting Glitches in Magnet Power Supplies at the APS Storage Ring," these proceedings (2001).

[3] Charles Schwartz et al., "A Localization Algorithm for Strong Sources of Orbit Motion in the APS Storage Ring," these proceedings (2001). 